\title{
Alogliptin in combination with metformin and pioglitazone for the treatment of type 2 diabetes mellitus
}

This article was published in the following Dove Press journal: Diabetes, Metabolic Syndrome and Obesity: Targets and Therapy 3 July 2014

Number of times this article has been viewed

\author{
Daniel Q Holland \\ Joshua J Neumiller \\ Department of Pharmacotherapy, \\ College of Pharmacy, Washington \\ State University, Spokane, \\ Washington, USA
}

Correspondence: Joshua J Neumiller Department of Pharmacotherapy, College of Pharmacy, Washington State University, PO Box 1495, Spokane, WA 99210-1495, USA

Tel +I 5093686756

Fax + I 8885576162

Email jneumiller@wsu.edu

\begin{abstract}
Alogliptin is a selective dipeptidyl peptidase-4 inhibitor recently marketed for once-daily administration in the treatment of type 2 diabetes mellitus (T2DM). Fixed-dose combinations of alogliptin with both metformin and pioglitazone are also commercially available, providing a measure of convenience in addition to an effective mode of delivering combination therapy to improve glycemic control. Alogliptin has been studied clinically as initial therapy in treatmentnaïve patients with T2DM and as initial therapy or add-on in combination with other antidiabetic agents. Clinical trial data with alogliptin demonstrate clinical efficacy in terms of glycosylated hemoglobin A1c and fasting plasma glucose reductions when used both as monotherapy and as a component of two- or three-drug combination regimens for the treatment of T2DM. Extensive Phase II and Phase III clinical trial data support the use of alogliptin in combination with metformin and pioglitazone. Glycemic reduction with both combinations is similar to the sum of the respective monotherapies, with adverse event rates similar - or more moderate - than those observed with up-titration of monotherapy or the addition of other antihyperglycemic agents.
\end{abstract}

Keywords: antidiabetic, diabetes management, DPP-4 inhibitor, fixed-dose combination, incretin therapy

\section{Introduction}

Advancement in the knowledge surrounding the physiology of endogenous glucoregulatory peptide hormones, namely glucose-dependent insulinotropic polypeptide (GIP) and glucagon-like peptide-1 (GLP-1), has led to a rapid expansion in the availability of agents utilizing the incretin system for the treatment of type 2 diabetes mellitus (T2DM). Dipeptidyl peptidase-4 (DPP-4) inhibitors are one such class of agents that provide clinicians with a novel mechanism of action to utilize, often in combination with other therapies, for the treatment of T2DM. In fact, current clinical recommendations and guidelines advocate for the use of combination therapy approaches taking advantage of different, yet complementary, mechanisms of action to achieve glycemic goals. ${ }^{1,2}$ While alogliptin has been studied in a variety of combination studies including, but not limited to, as add-on to glyburide ${ }^{3}$ and insulin, ${ }^{4}$ this article will focus on clinical data pertaining to alogliptin used as monotherapy and as combination therapy with metformin and pioglitazone. Alogliptin is commercially available in fixed-dose combination with metformin (Kazano ${ }^{\mathrm{TM}}$; Takeda Pharmaceutical Company, Osaka, Japan) and pioglitazone (Oseni ${ }^{\text {TM}}$; Takeda Pharmaceutical Company). In light of these available fixed-dose combination products, the clinical efficacy and safety data of alogliptin combination therapy will be highlighted and discussed. 


\section{Materials and methods}

A MEDLINE ${ }^{\circledR}$ search (1966-February 2014) was conducted with the keywords "alogliptin", "metformin", "pioglitazone", "Nesina", "Oseni”, "Kazano", "incretin”, and "DPP-4 inhibitor" for published clinical trials and pertinent review articles published in English. References of identified articles were searched for additional relevant sources. Articles relevant to the safety, efficacy, and pharmacology of alogliptin combinations were also identified from the references cited in works obtained from ClinicalTrials.gov and MEDLINE search results.

\section{Pharmacology}

The "incretin effect" is noted to be responsible for approximately $60 \%$ of postprandial insulin response, and results from peptide hormones released by the intestine in response to oral intake of nutrients. ${ }^{5}$ Two incretin hormones are primarily associated with this effect. GLP-1 is produced by intestinal L-cells, and, in addition to stimulating insulin secretion in pancreatic $\beta$-cells, suppresses glucose-dependent glucagon secretion, induces satiety, and slows gastric emptying. ${ }^{6}$ GIP, produced by duodenal cells, also stimulates insulin secretion but does not suppress glucagon release. ${ }^{7-10}$ Both GIP and GLP-1 are metabolized by the DPP-4 enzyme. DPP-4 is a 110 $\mathrm{kDa}$ transmembrane aminopeptidase that cleaves $\mathrm{N}$-terminal dipeptides from proteins containing proline or alanine in the second position (Xaa-Pro- or Xaa-Ala-). ${ }^{11}$ DPP-4 is expressed in many different tissues, is known to be present and active in plasma when its active domain is cleaved from membranebound domains, and is also known as the cluster of differentiation (CD)-26 antigen when expressed in lymphocytes. ${ }^{11}$ Alogliptin is a pyrimidine in structure and reversibly binds at the active catalytic site on the DPP-4 enzyme. ${ }^{12}$

As a DPP-4 inhibitor, alogliptin reduces glycosylated hemoglobin (A1c) and postprandial plasma glucose (PPG) levels by slowing the degradation of GLP-1 and GIP, in turn increasing plasma concentrations of the active peptides. ${ }^{8,11,13}$ Because the glucose-lowering effects of DPP-4 inhibitors are dependent on the presence of dietary glucose, alogliptin itself presents a relatively low risk for hypoglycemia relative to insulin secretagogues and other antihyperglycemic agents. ${ }^{11}$

Alogliptin (Figure 1) is highly selective for the DPP-4 enzyme: half-maximal inhibitory concentrations $\left(\mathrm{EC}_{50}\right)$ for the structurally similar enzymes DPP-2, DPP-8, DPP-9, and fibroblast activation protein are $>10,000 \times$ the $\mathrm{EC}_{50}$ for DPP-4. . $^{8,11,14}$ Alogliptin preferentially inhibits DPP-4 over DPP-8 or DPP-9 by a factor of more than $14,000 .{ }^{12}$ Inhibition of related

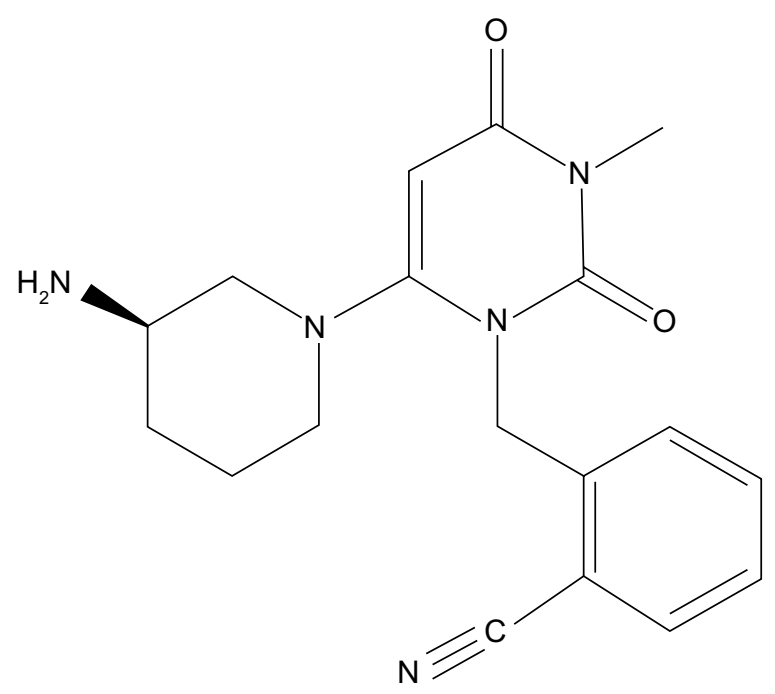

Figure I Chemical structure of alogliptin.

proteases, particularly DPP-8 and DPP-9, has been associated with toxicity in animal models and reduced activation of human T-cells, making selectivity a desirable attribute and a likely contributor to the generally sound safety profile associated with alogliptin monotherapy. ${ }^{8,15}$

\section{Pharmacokinetics and pharmacodynamics}

In a trial of alogliptin in 54 adult T2DM patients, $25 \mathrm{mg}$ once-daily dosing of alogliptin produced a time following administration to maximum plasma concentration $\left(\mathrm{T}_{\max }\right)$ of 1-2 hours, half-life $\left(t_{1 / 2}\right)$ of approximately 21 hours (standard deviation $[\mathrm{SD}]=8.8$ ), and an approximately linear relationship between dose and area under the curve (AUC) throughout and well beyond the therapeutic range. ${ }^{8,12} \mathrm{~A}$ trial of single increasing doses in healthy male subjects showed similar pharmacokinetic parameters for therapeutic doses (25 mg), with no dose-limiting toxicity with single doses of up to $800 \mathrm{mg} .{ }^{13}$ Alogliptin has a reported $\mathrm{EC}_{50}$ of $6.6 \mathrm{ng} / \mathrm{mL}$, with peak inhibition ranging from $94 \%$ to $99 \%$, and inhibition at 24 hours in the range of $81 \%$ to $97 \%$ after 14 days at the approved once-daily $25 \mathrm{mg}$ dose. ${ }^{6}$ Once-daily administration of alogliptin $25 \mathrm{mg}$ increases the AUC of active GLP-1 by approximately two- to threefold.

Alogliptin is primarily excreted renally, with $60 \%-71 \%$ excreted unchanged in the urine within 72 hours of dosing. Renal clearance after 14 days of $25 \mathrm{mg}$ /day dosing was approximately $175-200 \mathrm{~mL} /$ minute, suggesting some level of active renal secretion. ${ }^{8,13,16} \mathrm{~A}$ single-dose pharmacokinetic evaluation of alogliptin in patients with moderate hepatic impairment (Child-Pugh score of 7-9) showed the maximum 
concentration $\left(\mathrm{C}_{\max }\right)$ and AUC of alogliptin decreased by approximately $10 \%$, while the $\mathrm{T}_{\max }$ increased by 2.5 hours. $^{17}$ Inactive metabolites form a minor portion of the elimination pathway, and are also excreted renally. ${ }^{16}$

In a study by Karim and colleagues, patients were stratified by age, race, and sex and administered alogliptin $25 \mathrm{mg}$ on day 1 and days $4-8 .{ }^{18}$ Clinically significant changes in alogliptin exposure were not seen between groups, although exposure was increased in the elderly when compared with the young, in white people compared with black people, and in female subjects relative to male subjects. ${ }^{18}$ However, age, race, and sex did not appear to alter DPP-4 inhibition, indicating that dosage adjustments are not needed based on these patient characteristics. ${ }^{18}$

Alogliptin absorption is substantially unchanged when administered with food, with no change in the $\mathrm{AUC}_{0-\infty}$ and a clinically insignificant reduction in $\mathrm{C}_{\max }{ }^{19} \mathrm{Co}$-administration of pioglitazone and alogliptin results in a slight decrease in alogliptin $\mathrm{T}_{\max }$ with an approximately $10 \%$ increase in $\mathrm{C}_{\max }$ and AUC. ${ }^{16}$ Trough concentrations of alogliptin were also increased by approximately $14 \%$. However, these interactions were regarded as clinically nonsignificant and $90 \%$ confidence intervals were within the bioequivalence range of $0.8-1.25$. A two-phase crossover study conducted by Karim et a $\mathrm{l}^{19}$ found that alogliptin did not affect metformin $\mathrm{C}_{\max }$ and had a clinically insignificant effect on metformin AUC. Metformin had no effect on alogliptin pharmacokinetic parameters. ${ }^{19}$

\section{Efficacy: clinical trial data}

As noted previously, while alogliptin has been studied in combination and as add-on to a variety of background therapies, clinical trial data with alogliptin in combination with metformin and pioglitazone are highlighted herein. As a basis of comparison, a brief discussion of alogliptin monotherapy is first presented. Table 1 provides a summary of select efficacy data from the clinical studies described in the following sections. ${ }^{20-26}$

\section{Alogliptin monotherapy in drug-naïve patients}

Prior to discussing the clinical efficacy of alogliptin as a component of combination therapy, it is useful to examine its effectiveness as monotherapy in drug-naïve individuals. Accordingly, two studies with alogliptin used as monotherapy in drug-naïve patients are briefly described here.

Table I Select efficacy outcomes from alogliptin clinical trials

\begin{tabular}{|c|c|c|c|c|c|c|c|c|}
\hline \multirow[t]{2}{*}{ Study } & \multirow{2}{*}{$\begin{array}{l}\text { Pts } \\
\text { (n) }\end{array}$} & \multicolumn{2}{|l|}{ Treatment } & \multirow{2}{*}{$\begin{array}{l}\text { Treatment } \\
\text { period } \\
\text { (weeks) }\end{array}$} & \multirow{2}{*}{$\begin{array}{l}\text { Alc } \\
\text { change } \\
(\%)\end{array}$} & \multirow{2}{*}{$\begin{array}{l}\text { Achievement } \\
\text { of Alc } \leq 7 \% \\
\text { (\%) }\end{array}$} & \multirow{2}{*}{$\begin{array}{l}\text { FPG } \\
\text { change } \\
(\mathrm{mg} / \mathrm{dL})\end{array}$} & \multirow{2}{*}{$\begin{array}{l}\text { BW } \\
\text { change } \\
(\mathrm{kg})\end{array}$} \\
\hline & & Background & $\begin{array}{l}\text { Treatment group } \\
\text { (intervention, } \mathrm{mg} \text { ) }\end{array}$ & & & & & \\
\hline Nauck & 527 & MET $\geq I, 500 \mathrm{mg}$ & PBO & 26 & -0.1 & 18 & 0 & - \\
\hline \multirow[t]{2}{*}{ et $\mathrm{al}^{20}$} & & & ALO I 2.5 & & $-0.6^{\mathrm{a}}$ & $52^{\mathrm{a}}$ & $-19^{a}$ & $0.0^{\mathrm{b}}$ \\
\hline & & & ALO 25 & & $-0.6^{\mathrm{a}}$ & $44^{\mathrm{a}}$ & $-17^{a}$ & $-0.3^{b}$ \\
\hline Seino & 288 & MET 500 or & PBO & 12 & 0.21 & 2.0 & -0.80 & -0.23 \\
\hline \multirow[t]{2}{*}{ et $\mathrm{al}^{21}$} & & $750 \mathrm{mg}$ & ALO I 2.5 & & $-0.54^{\mathrm{a}}$ & $28.3^{c}$ & $-19.0^{a}$ & $0.17^{c}$ \\
\hline & & & ALO 25 & & $-0.64^{\mathrm{a}}$ & $27.1^{c}$ & $-23 . I^{a}$ & -0.09 \\
\hline Rosenstock & 655 & Drug naïve & ALO 25 & 26 & -0.96 & 24.4 & -25.2 & -0.29 \\
\hline \multirow[t]{3}{*}{ et $\mathrm{al}^{22}$} & & & PIO 30 & & -1.15 & 33.7 & -37.8 & 2.19 \\
\hline & & & ALO I 2.5 + PIO 30 & & $-1.56^{\mathrm{d}}$ & $53.4^{d}$ & $-48.6^{d}$ & 2.51 \\
\hline & & & ALO $25+$ PIO 30 & & $-\left.1.7\right|^{\mathrm{d}, \mathrm{e}}$ & $62.8^{\mathrm{d}, \mathrm{e}}$ & $-50.5^{\mathrm{d}, \mathrm{e}}$ & $3.14^{\mathrm{d}, \mathrm{e}}$ \\
\hline \multirow[t]{3}{*}{ Kaku et $\mathrm{a}^{23}$} & 339 & PIO I5-30 mg & PBO & 12 & -0.19 & $20^{\mathrm{g}}$ & -2.4 & -0.03 \\
\hline & & & ALO I 2.5 & & $-0.9 I^{f}$ & $49.5^{f, g}$ & $-14.9^{f}$ & $0.48^{f}$ \\
\hline & & & ALO 25 & & $-0.97^{f}$ & $49.6^{\mathrm{fg} g}$ & $-18.9^{f}$ & $0.46^{f}$ \\
\hline DeFronzo & I,554 & MET $\geq I, 500 \mathrm{mg}$ & PIO I5-45 & 26 & -0.9 & 30.5 & -28.8 & 1.5 \\
\hline \multirow[t]{2}{*}{ et $\mathrm{a}^{24}$} & & & PIO I5-45 + ALO I 2.5 & & $-1.4^{\mathrm{h}}$ & $54.6^{\mathrm{h}}$ & $-45.0^{\mathrm{h}}$ & 1.8 \\
\hline & & & $\mathrm{PIO} 15-45$ + ALO 25 & & $-1.4^{\mathrm{h}}$ & $55.9^{\mathrm{h}}$ & $-45.0^{h}$ & 1.9 \\
\hline \multirow[t]{2}{*}{ Bosi et a ${ }^{25}$} & 803 & MET $\geq 1,500 \mathrm{mg}$ & $\mathrm{PIO} 45$ & 52 & -0.29 & 21.3 & -3.6 & 1.6 \\
\hline & & or MTD & $\mathrm{PIO} 30+\mathrm{ALO} 25$ & & $-0.70^{h}$ & $33.2^{\mathrm{h}}$ & $-14.4^{\mathrm{h}}$ & 1.1 \\
\hline Pratley & 493 & $\mathrm{PIO} \pm \mathrm{MET} / \mathrm{SU}$ & PBO & 26 & -0.19 & 34.0 & -5.7 & - \\
\hline \multirow[t]{2}{*}{ et $\mathrm{a}^{26}$} & & & ALO I 2.5 & & $-0.66^{\mathrm{a}}$ & $44.2^{i}$ & $-19.7^{j}$ & $0.42^{\mathrm{b}}$ \\
\hline & & & ALO 25 & & $-0.80^{\mathrm{a}}$ & $49.2^{i}$ & $-19.9 j$ & $0.05^{b}$ \\
\hline
\end{tabular}

Notes: ${ }^{a} P<0.00$ I versus placebo; bleast-squares mean difference relative to placebo; 'statistically significant versus change with $M E T$ monotherapy; ${ }^{\mathrm{d}} \mathrm{P}<0.05$ versus $\mathrm{PIO} 30$;

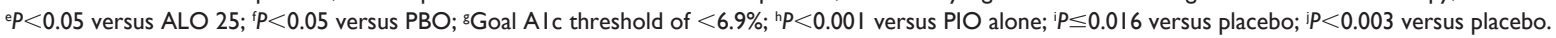

Abbreviations: A l c, glycosylated hemoglobin; ALO, alogliptin; BW, body weight; FPG, fasting plasma glucose; MET, metformin; MTD, maximum tolerated dose; PBO, placebo; PIO, pioglitazone; PPG, postprandial glucose; Pts, participants randomized; SU, sulfonylurea. 
The first study was a double-blind, placebo-controlled, multicenter trial enrolling 329 participants with T2DM. ${ }^{27}$ This trial compared 26 weeks of treatment with alogliptin $12.5 \mathrm{mg}$ daily $(\mathrm{n}=133)$, alogliptin $25 \mathrm{mg}$ daily $(\mathrm{n}=131)$, or placebo $(\mathrm{n}=65)$. Enrolled participants had a baseline A1c of $7 \%-10 \%$ despite lifestyle management for $\geq 1$ month, and a baseline body mass index of $23-45 \mathrm{~kg} / \mathrm{m}^{2}$. At 26 weeks, participants experienced a mean decrease in A1c from baseline of $-0.56,-0.59$, and $-0.02 \%$ in the alogliptin $12.5 \mathrm{mg}$, alogliptin $25.0 \mathrm{mg}$, and placebo groups, respectively $(P<0.001$ for both alogliptin groups when compared with placebo). These mean changes in A1c additionally led to a larger percent of alogliptin-treated participants achieving a goal A1c of $\leq 7.0 \%(47.4 \%, 44.3 \%$, and $23.4 \%$ in the three treatment groups, respectively). Participants receiving alogliptin likewise achieved a statistically significant reduction in fasting plasma glucose (FPG) values from baseline when compared with those receiving placebo $(P<0.001$ for both alogliptin groups versus placebo). Mean changes in FPG from baseline were $-10.3,-16.4$, and $+11.3 \mathrm{mg} / \mathrm{dL}$ in the three treatment groups, respectively. As would be expected with DPP-4 inhibitor monotherapy, hypoglycemic events were rare $(1.5 \%-3.0 \%)$ during the study, with no hypoglycemic events requiring third-party assistance.

Kutoh and Ukai ${ }^{28}$ conducted a randomized, non-doubleblind, non-inferiority trial to evaluate the efficacy and safety of alogliptin versus a low-fat/low-calorie traditional Japanese diet. Enrolled participants were newly diagnosed, drug-naïve Japanese patients with T2DM. Twenty-five participants were randomized to receive $12.5-25.0 \mathrm{mg}$ of alogliptin per day, with 26 participants randomized to receive treatment with a traditional Japanese diet. Participants randomized to the alogliptin arm had a mean A1c of $10.51 \%$, with those allocated to the dietary group having a mean baseline A1c of $10.01 \%$. Following 3 months of treatment, the mean A1c decrease from baseline in the alogliptin group was $1.77 \%$. However, there was no significant difference in A1c reduction between the two groups, with the $95 \%$ confidence intervals for A $1 \mathrm{c}$ change being $-2.44 \%$ to $-1.08 \%$ in the alogliptin arm and $-2.14 \%$ to $-1.08 \%$ in the diet group. During the 3 -month treatment period, four of the 25 participants in the alogliptin group reported mild hypoglycemic events.

\section{Alogliptin as add-on to metformin}

Several clinical trials have investigated the use of alogliptin as add-on to background metformin therapy. Nauck and colleagues ${ }^{20}$ conducted a 26-week, double-blind, randomized, placebo-controlled study in 527 participants with T2DM.
For inclusion in the study, participants were required to have a baseline A1c of 7.0\%-10.0\% and a body mass index of $23-45 \mathrm{~kg} / \mathrm{m}^{2}$. Enrolled participants had a mean baseline A1c of $7.9 \%-8.0 \%$, depending on the treatment group. Participants were required to receive a dose of metformin $\geq 1,500 \mathrm{mg}$ for at least 8 weeks and could not be receiving a medication for the treatment of T2DM other than metformin for the 3 months preceding screening. Participants were randomized to one of three study arms: addition of alogliptin $12.5 \mathrm{mg}(\mathrm{n}=213)$, alogliptin $25.0 \mathrm{mg}(\mathrm{n}=210)$, or placebo $(\mathrm{n}=104)$. For the primary efficacy end point of change in A1c at 26 weeks from baseline, both alogliptin arms achieved an A1c reduction of $0.6 \%$, compared with a reduction of $0.1 \%$ in the placebo group ( $P<0.001$ for both comparisons). Additionally, more participants receiving alogliptin achieved an A1c of $\leq 7.0 \%$ when compared with those in the placebo group $(P<0.001)$, and greater reductions in FPG from baseline were seen in the alogliptin $12.5 \mathrm{mg}$ and $25.0 \mathrm{mg}$ groups when compared with placebo $(-19,-17$, and $-0 \mathrm{mg} / \mathrm{dL}$ in the three treatment groups, respectively; $P<0.001)$.

Another study of alogliptin as add-on to metformin was conducted in a cohort of Japanese patients with T2DM. ${ }^{21}$ This randomized, double-blind, placebo-controlled study enrolled participants with a baseline A1c of between $6.9 \%$ and $10.4 \%$ who were receiving a stable dose of metformin for at least 12 weeks prior to screening. Participants underwent an initial 12-week observational period, during which they received $500 \mathrm{mg}$ or $750 \mathrm{mg}$ of metformin daily in addition to lifestyle education. Following the 12-week observational phase, participants $(\mathrm{N}=288)$ were randomized to continue metformin therapy in addition to either alogliptin $12.5 \mathrm{mg}$ $(n=92)$, alogliptin $25.0 \mathrm{mg}(\mathrm{n}=96)$, or placebo $(\mathrm{n}=100)$ for an additional 12-week period (weeks 13-24). Select 12-week efficacy data are summarized in Table 1. Of note, participants in the metformin plus alogliptin dual-therapy groups exhibited statistically significant improvements in A1c, FPG, and achievement of an A1c $\leq 7.0 \%$ when compared with the metformin plus placebo group. In that study, PPG levels were also assessed, and statistically significant reductions in PPG were demonstrated with alogliptin therapy as add-on to metformin versus placebo. PPG levels were decreased by $33.6 \mathrm{mg} / \mathrm{dL}$ in the alogliptin $12.5 \mathrm{mg}$ group, $42.9 \mathrm{mg} / \mathrm{dL}$ in the alogliptin $25 \mathrm{mg}$ group, and $3.1 \mathrm{mg} / \mathrm{dL}$ in the placebo group. Following the 12-week efficacy phase (weeks 13-24), participants in the placebo group were randomized equally to receive alogliptin 12.5 or $25.0 \mathrm{mg}$ daily in addition to metformin and continue treatment for an additional 40 weeks in an open-label extension period. When analyzing all randomized patients 
receiving at least one dose of study medication, mean A1c reductions from week 0 to week 52 were $0.44 \%$ and $0.58 \%$ in the alogliptin $12.5 \mathrm{mg}$ and alogliptin $25.0 \mathrm{mg}$ plus metformin groups, respectively.

\section{Alogliptin plus pioglitazone as initial therapy in drug-naïve patients}

A study involving T2DM patients naïve to T2DM drug therapy was conducted by Rosenstock and colleagues. ${ }^{22}$ The study was performed to assess the efficacy and tolerability of alogliptin in combination with pioglitazone for the initial treatment of drug-naïve patients with inadequate glycemic control (baseline A $1 \mathrm{c}$ of $7.5 \%-11 \%$ ), with the mean baseline A1c ranging from $8.76 \%$ to $8.85 \%$ in the various treatment groups. This 26-week, double-blind, parallel-group study enrolled 655 participants who were randomized to receive alogliptin $25.0 \mathrm{mg}$ daily ( $\mathrm{n}=164)$, pioglitazone $30.0 \mathrm{mg}$ daily ( $\mathrm{n}=163)$, alogliptin $12.5 \mathrm{mg}$ daily plus pioglitazone $30.0 \mathrm{mg}$ daily ( $\mathrm{n}=163$ ), or alogliptin $25.0 \mathrm{mg}$ daily plus pioglitazone $30.0 \mathrm{mg}$ daily $(\mathrm{n}=164)$. Mean reductions in A $1 \mathrm{c}$ from baseline at 26 weeks were $-0.96 \%,-1.15 \%,-1.56 \%$, and $-1.71 \%$ in the four groups, respectively. In addition to seeing more A1c reduction in the alogliptin plus pioglitazone groups, a greater percentage of participants receiving combination therapy also achieved an A1c of $<7 \%$ at 26 weeks, as noted in Table 1 . Likewise, a statistically significant reduction in FPG was seen in the alogliptin $25 \mathrm{mg}$ daily plus pioglitazone $30 \mathrm{mg}$ daily group when compared with either of the monotherapy groups. When looking at changes in body weight over 26 weeks in the four groups, a statistically significant weight gain was seen in the alogliptin $25 \mathrm{mg}$ daily plus pioglitazone $30 \mathrm{mg}$ daily group when compared with either the alogliptin $25 \mathrm{mg}$ daily or pioglitazone $30 \mathrm{mg}$ daily groups. While the reason for this increase in body weight was not discussed within the research report, it raises the question of additive edema when these agents are used in combination. Given these results, the authors concluded that the combination of alogliptin and pioglitazone appears to be an effective initial treatment option in patients with T2DM.

\section{Alogliptin as add-on to pioglitazone}

A 12-week, randomized, double-blind, placebo-controlled trial assessing the efficacy and safety of alogliptin as add-on to pioglitazone was conducted in Japanese participants with T2DM. ${ }^{23}$ Participants were $\geq 20$ years of age, had an A1c of between $6.9 \%$ and $10.4 \%$, and were receiving a stable dose of pioglitazone (15 or $30 \mathrm{mg} /$ day) in addition to diet and exercise for at least 16 weeks. Participants could not have received another antihyperglycemic medication within the previous 16 weeks. Eligible participants were stratified based on pioglitazone dose and randomized to receive the addition of alogliptin $12.5 \mathrm{mg}(\mathrm{n}=111)$, alogliptin $25.0 \mathrm{mg}(\mathrm{n}=113)$, or placebo $(n=115)$. Mean baseline A1c values in the three study groups ranged from $7.89 \%$ to $7.92 \%$. A summary of select efficacy end points can be found in Table 1. Of note, for the primary end point of change in A1c from baseline to week 12 , mean A1c reductions from baseline were $0.91 \%$, $0.97 \%$, and $0.19 \%$ in the alogliptin $12.5 \mathrm{mg}$, alogliptin $25.0 \mathrm{mg}$, and placebo groups, respectively $(P<0.0001$ for both alogliptin comparisons versus placebo). Statistically significant improvements were additionally noted with alogliptin add-on to pioglitazone versus placebo for achieving of an A1c $<6.9 \%$ and changes from baseline in FPG and PPG.

\section{Alogliptin plus pioglitazone as add-on to metformin}

A study in 1,554 participants with T2DM was conducted to assess the efficacy and tolerability of alogliptin combined with pioglitazone as add-on therapy to metformin. ${ }^{24}$ This 26-week, randomized, double-blind, placebo-controlled study included patients with an A1c of $7.5 \%-10.0 \%$ receiving $\geq 1,500 \mathrm{mg}$ /day of metformin as monotherapy. Eligible participants were randomized to receive metformin plus placebo, alogliptin (12.5 or $25.0 \mathrm{mg}$ daily) plus metformin, pioglitazone $(15,30$ or $45 \mathrm{mg}$ /day) plus metformin, or alogliptin (12.5 or $25.0 \mathrm{mg}$ daily) combined with pioglitazone (15, 30 or $45 \mathrm{mg} /$ day) plus metformin. When assessing the change in A1c from baseline at 26 weeks, the pioglitazone plus metformin pooled group achieved a mean A1c reduction from baseline of $0.9 \%$. In contrast, participants receiving triple therapy (alogliptin, pioglitazone, and metformin) achieved a mean A1c reduction of $1.4 \%(P<0.001$ versus pioglitazone plus metformin pooled group). Of note, groups receiving dual therapy (alogliptin plus metformin or pioglitazone plus metformin) exhibited a higher percentage of patients requiring hyperglycemic rescue $(8.5 \%-14.7 \%)$ when compared with any triple-therapy group $(1.5 \%-4.6 \%)$. Additional select efficacy data are provided in Table 1 . These findings suggest that the addition of alogliptin and pioglitazone to patients inadequately controlled on metformin monotherapy resulted in an additive reduction in A1c.

\section{Alogliptin as add-on to pioglitazone plus or minus metformin}

A 52-week study to assess the efficacy and safety of adding alogliptin versus up-titrating pioglitazone in patients 
with T2DM and inadequate glycemic control (A1c of $7.0 \%-10.0 \%$ ) despite metformin plus pioglitazone dual therapy was published by Bosi and colleagues. ${ }^{25}$ Eligible participants were either 1 ) receiving $\geq 1,500 \mathrm{mg}$ of metformin (or maximum tolerated dose) plus pioglitazone $30 \mathrm{mg} /$ day for at least 2 months prior to screening or 2) had an A1c of $\geq 7.5 \%$ while receiving metformin plus another oral antidiabetic agent (excluding pioglitazone or a DPP-4 inhibitor) and had a subsequent A1c of between $7.0 \%$ and $10.0 \%$ after switching to metformin plus pioglitazone $30 \mathrm{mg}$ / day for at least 16 weeks. Study participants were randomized to receive either metformin plus pioglitazone $45 \mathrm{mg} /$ day $(\mathrm{n}=399)$ or metformin plus pioglitazone $30 \mathrm{mg} /$ day plus alogliptin $25 \mathrm{mg} /$ day $(\mathrm{n}=404)$. Select efficacy data are provided in Table 1. Of note, participants in the triple-therapy arm had statistically significant reductions from baseline in A1c and FPG when compared with up-titration of pioglitazone, with a numerically greater weight gain in the pioglitazone up-titration group observed.

\section{Alogliptin as add-on to pioglitazone plus or minus metformin and/or sulfonylurea}

The efficacy and safety of alogliptin as add-on to pioglitazone plus or minus concomitant metformin or a sulfonylurea was assessed in a double-blind placebo-controlled study. ${ }^{26}$ Participants, aged 18-80, had inadequate glycemic control at the time of enrollment (A1c of 7\%-10\%). Participants were randomized to receive add-on therapy of alogliptin $12.5 \mathrm{mg}$ $(n=197)$, alogliptin $25.0 \mathrm{mg}(\mathrm{n}=199)$, or placebo $(\mathrm{n}=97)$ for 26 weeks. Following 26 weeks of treatment, the mean A1c reductions from baseline were $-0.66,-0.8$ and $-0.19 \%$ in the alogliptin $12.5 \mathrm{mg}, 25.0 \mathrm{mg}$, and placebo groups, respectively ( $P<0.001$ for both alogliptin groups versus placebo). A significantly larger $(P \leq 0.016)$ proportion of participants in the alogliptin groups achieved an A $1 \mathrm{c}$ of $\leq 7 \%$ at 26 weeks when compared with the placebo group. FPG reductions from baseline were also greater in the alogliptin groups, with mean reductions of $-19.7,-19.9$, and $-5.7 \mathrm{mg} / \mathrm{dL}$ noted in the three treatment groups, respectively.

\section{Alogliptin use in patients with kidney disease}

Given the low risk of hypoglycemia and the weight neutrality of the DPP-4 inhibitors, they have gained interest as potentially useful agents in people with T2DM and reduced kidney function. Diabetes itself is a major risk factor for the development of chronic kidney disease, ${ }^{29}$ and several studies have even suggested a renal protective effect with
DPP-4 inhibitors. ${ }^{30,31}$ Alogliptin is primarily eliminated renally, with exposure increasing incrementally with a decline in renal function. ${ }^{32,33}$ Several studies have examined alogliptin use in patients with kidney disease. ${ }^{32,33}$ Nakamura and colleagues enrolled 16 participants with T2DM receiving hemodialysis (HD). ${ }^{32}$ Enrolled participants had inadequate glycemic control (defined as an A1c of $>6.5 \%$ ) from management with diet and exercise alone. No participants were receiving antidiabetic therapy at the time of enrollment. Participants were initiated on alogliptin $6.25 \mathrm{mg}$ once daily. At the conclusion of the study period, mean A1c values decreased from $7.1 \%$ at baseline to $5.8 \%$ after 24 months of treatment. During the 24-month study, only one serious adverse event (AE) was reported, which was a drug-related rash experienced by one study participant.

Another prospective open-label study was conducted in 30 T2DM participants undergoing HD three times weekly. ${ }^{33}$ Study participants received mitiglinide and/or voglibose during an 8-week observational period, after which they were started on $6.25 \mathrm{mg}$ of alogliptin once daily in addition to their background therapy. Following a 48-week treatment period, mean A1c values decreased from $7.1 \%$ at baseline to $6.3 \%$ $(P<0.0001)$. Mean PPG levels additionally declined from $212 \mathrm{mg} / \mathrm{dL}$ at baseline to $156 \mathrm{mg} / \mathrm{dL}$ at week $48(P<0.0001)$. No subjects discontinued treatment due to AEs.

While the studies described have been relatively small, they provide support for the efficacy and safety of alogliptin in patients with reduced renal function, including patients with end stage renal disease receiving HD.

\section{Safety and tolerability}

Safety and tolerability data from select Phase III clinical trials and post-marketing reports are discussed in this section. Overall, alogliptin monotherapy is generally well tolerated in most patients, with a generally mild overall side-effect (SE) profile. However, when considering the safety and tolerability of fixed-dose combination products containing alogliptin, safety considerations for both active ingredients must be considered. Table 2 provides select safety and tolerability information from clinical trials included in this review. ${ }^{20,21,23-26}$ First, safety data from trials with alogliptin in combination with metformin and pioglitazone, respectively, are presented. Second, safety issues of special interest are briefly discussed.

\section{Alogliptin in combination with metformin}

A review of clinical trials evaluating alogliptin in combination with metformin consistently indicates SE and 
Table 2 Select adverse-drug-event rates from selected alogliptin clinical trials

\begin{tabular}{|c|c|c|c|c|c|c|c|c|}
\hline Study & $\begin{array}{l}\text { Treatment } \\
\text { group } \\
\text { (intervention, } \\
\text { mg) }\end{array}$ & $\begin{array}{l}\text { Discontinuation } \\
\text { due to AE } \\
\text { (n [\%]) }\end{array}$ & $\begin{array}{l}\text { Diarrhea } \\
\text { (n [\%]) }\end{array}$ & $\begin{array}{l}\text { Nasopharyngitis } \\
\text { (n [\%]) }\end{array}$ & $\begin{array}{l}\text { Arthralgia } \\
\text { (n [\%]) }\end{array}$ & $\begin{array}{l}\text { Headache } \\
\text { (n [\%]) }\end{array}$ & $\begin{array}{l}\text { Severe } \\
\text { hypoglycemia } \\
\text { (n [\%]) }\end{array}$ & $\begin{array}{l}\text { Peripheral } \\
\text { edema } \\
(\mathrm{n}[\%])\end{array}$ \\
\hline Nauck & $\mathrm{MET}+\mathrm{PBO}$ & $I(I)$ & $6(6)$ & $6(6)$ & $5(5)$ & $2(2)$ & $0(0)$ & $N R$ \\
\hline \multirow[t]{2}{*}{ et $\mathrm{a}^{20}$} & MET + ALO 12.5 & $7(3)$ & $6(3)$ & $12(6)$ & $4(2)$ & $8(4)$ & $0(0)$ & $N R$ \\
\hline & MET + ALO 25 & $4(2)$ & $7(3)$ & $7(3)$ & $3(1)$ & $4(2)$ & $0(0)$ & $N R$ \\
\hline Seino & $\mathrm{MET}+\mathrm{PBO}$ & $0(0)$ & $I(I)$ & $20(20.0)$ & $0(0)$ & $0(0)$ & $0(0)$ & NR \\
\hline \multirow[t]{2}{*}{ et $\mathrm{al}^{21}$} & MET + ALO I2.5 & $0(0)$ & $5(5.4)$ & $18(19.6)$ & $0(0)$ & $6(6.5)$ & $0(0)$ & NR \\
\hline & $\mathrm{MET}+\mathrm{ALO} 25$ & $0(0)$ & $I(I)$ & $22(22.9)$ & $I(I)$ & $0(0)$ & $0(0)$ & $N R$ \\
\hline Kaku & $\mathrm{PIO}+\mathrm{PBO}$ & $4(3.5)$ & NR & $6(5.2)$ & NR & NR & $0(0)$ & $2(1.7)$ \\
\hline \multirow[t]{2}{*}{ et $\mathrm{a}^{23}$} & $\mathrm{PIO}+\mathrm{ALO} 12.5$ & I (0.9) & $N R$ & $5(4.5)$ & $2(1.8)$ & NR & $0(0)$ & $0(0)$ \\
\hline & $\mathrm{PIO}+\mathrm{ALO} 25$ & $2(1.8)$ & NR & $(12.4)$ & $(9.1)$ & NR & $0(0)$ & $(2.7)$ \\
\hline DeFronzo & $\mathrm{MET}+\mathrm{PIO}+\mathrm{PBO}$ & II (2.8) & $14(3.6)$ & II (2.8) & $13(3.4)$ & $23(5.9)$ & $2(0.5)$ & $10(2.6)$ \\
\hline \multirow[t]{2}{*}{ et $\mathrm{a}^{24}$} & $\begin{array}{l}\text { MET + PIO + } \\
\text { ALO I } 2.5\end{array}$ & $8(2.1)$ & $9(2.3)$ & $19(4.9)$ & II (2.8) & $13(3.3)$ & $0(0)$ & $10(2.6)$ \\
\hline & $\begin{array}{l}\text { MET + PIO + } \\
\text { ALO } 25\end{array}$ & $6(1.5)$ & $20(5.1)$ & $21(5.4)$ & $12(3.1)$ & $14(3.6)$ & $\mathrm{I}(0.3)$ & $14(3.6)$ \\
\hline \multirow[t]{2}{*}{$\begin{array}{l}\text { Bosi } \\
\text { et } \mathrm{al}^{25}\end{array}$} & $\begin{array}{l}\text { MET + PIO } 30+ \\
\text { ALO } 25\end{array}$ & $12(3.0)$ & II (2.7) & $28(6.9)$ & $13(3.2)$ & $19(4.7)$ & $2(0.5)$ & $16(4.0)$ \\
\hline & MET + PIO 45 & $16(4.0)$ & $24(6.0)$ & $21(5.3)$ & $13(3.3)$ & $16(4.0)$ & $0(0)$ & $18(4.5)$ \\
\hline \multirow[t]{3}{*}{$\begin{array}{l}\text { Pratley } \\
\text { et } \mathrm{al}^{26}\end{array}$} & $\begin{array}{l}\mathrm{PIO}+\mathrm{PBO} \pm \\
\mathrm{MET} / \mathrm{SU}\end{array}$ & $3(3.1)$ & NR & $6(6.2)$ & NR & $4(4.1)$ & NR & $7(7.2)$ \\
\hline & $\begin{array}{l}\mathrm{PIO}+\mathrm{ALO} I 2.5 \pm \\
\mathrm{MET} / \mathrm{SU}\end{array}$ & $6(3.0)$ & NR & $8(4.0)$ & $N R$ & $8(4.0)$ & $N R$ & $12(6.1)$ \\
\hline & $\begin{array}{l}\mathrm{PIO}+\mathrm{ALO} 25 \pm \\
\mathrm{MET} / \mathrm{SU}\end{array}$ & $6(3.0)$ & $N R$ & $14(7.0)$ & $N R$ & $10(5.0)$ & NR & II (5.5) \\
\hline
\end{tabular}

Abbreviations: AE, adverse event; ALO, alogliptin; MET, metformin; NR, not reported; PBO, placebo; PIO, pioglitazone; SU, sulfonylurea.

adverse-drug-event rates that are additive and characteristic of the therapeutic agents when utilized individually.

Nauck et al evaluated alogliptin added to metformin in participants with $\mathrm{T} 2 \mathrm{DM}$ inadequately controlled with metformin alone (A1c 7\%-10\%); patients were randomized to receive placebo $(\mathrm{n}=104)$, alogliptin $12.5 \mathrm{mg}$ once daily $(\mathrm{n}=213)$, or alogliptin $25.0 \mathrm{mg}$ once daily $(\mathrm{n}=210)$, in addition to continued stable daily dosing of at least $1,500 \mathrm{mg}$ of metformin. ${ }^{20}$ The percentage of patients experiencing more than one $\mathrm{AE}$ in each group was $66 \%$, $63 \%$, and $57 \%$ in the placebo, alogliptin $12.5 \mathrm{mg}$, and alogliptin $25.0 \mathrm{mg}$ groups, respectively. The percentages of patients with AEs considered drug related were also similar across all groups $(10 \%, 11 \%$, and $13 \%$, respectively), as were the frequencies of serious AEs (4\%, 3\%, and $4 \%$, respectively). Episodes of hypoglycemia were marginally higher in the metformin plus placebo group $(n=3,3 \%)$, with two patients $(1 \%)$ in the metformin plus alogliptin $12.5 \mathrm{mg}$ group and no patients in the metformin plus alogliptin $25 \mathrm{mg}$ group experiencing a hypoglycemic event. All instances of hypoglycemia were deemed by investigators to be both non-serious and clinically insignificant. Overall, AEs were substantially similar across all three study groups.

Seino et al evaluated alogliptin with metformin in Japanese patients with T2DM for 12 weeks, with a 52-week extension. Patients were randomized to receive metformin with either placebo ( $\mathrm{n}=100)$, alogliptin $12.5 \mathrm{mg}$ daily $(\mathrm{n}=92)$, or alogliptin $25.0 \mathrm{mg}$ daily $(\mathrm{n}=96) .{ }^{21}$ The most commonly reported AE was nasopharyngitis, with rates of $20.0 \%$ in the monotherapy group, $19.6 \%$ in the alogliptin $12.5 \mathrm{mg}$ group, and $22.9 \%$ in the alogliptin $25.0 \mathrm{mg}$ group reported. Headache, constipation, back pain, eczema, and diarrhea were also common, although no clear trends were evident among the treatment and control groups. A total of six patients receiving alogliptin reported mild skin eruptions, while none were reported in the metformin monotherapy cohort. In the course of the 52-week extension, approximately $78 \%$ of patients receiving alogliptin experienced an $\mathrm{AE}$, although only approximately $19 \%$ experienced an event judged possibly or probably drug related. No serious drug-related AEs were reported for the 12-week trial, while two serious treatment-related AEs were reported during the 52-week extension. These included infectious enteritis (alogliptin 12.5 
plus metformin), and cardiac failure (alogliptin $25.0 \mathrm{mg}$ plus metformin). No patients discontinued the study due to drugrelated AEs during the 12-week trial, while three patients discontinued for this reason in the 52-week extension.

Bosi et al evaluated alogliptin as a third agent in T2DM patients with inadequate glycemic control despite treatment with metformin and pioglitazone. ${ }^{25}$ The 52-week parallelgroup study observed patients treated with alogliptin $25 \mathrm{mg}$ plus pioglitazone $30 \mathrm{mg}$ plus metformin $(\geq 1,500 \mathrm{mg}$ or stabilized maximally tolerated dose, $n=404$ ) versus an uptitration of pioglitazone to $45 \mathrm{mg}$ with stable metformin dosing $(n=399)$. Rates of drug-related AEs were slightly higher in the triple-therapy group $(21.8 \%, \mathrm{n}=88)$ compared with in the metformin plus pioglitazone dual-therapy group (18.8\%, $\mathrm{n}=75$ ), with peripheral edema being the most common ( $2 \%$ and $3 \%$, respectively). The addition of alogliptin also resulted in a higher rate of skin and subcutaneous disorders $(5.1 \%$ versus [vs] $2.3 \%$, respectively), with pruritus and rash being the most common.

Overall, the addition of alogliptin to metformin resulted in additive therapeutic effects without any notable increase in body weight, hypoglycemic events, major cardiac events, or other AEs over metformin monotherapy. Additionally, none of the trials reviewed showed clinically meaningful changes in vital signs, electrocardiograms, serum chemistry, hematology, or urinalysis..$^{20,25}$

\section{Alogliptin in combination with pioglitazone}

Pratley et al evaluated alogliptin $12.5 \mathrm{mg}$, alogliptin $25.0 \mathrm{mg}$, or placebo with pioglitazone $30 \mathrm{mg}$ or $45 \mathrm{mg}$ once daily in 493 T2DM patients for 26 weeks. ${ }^{26}$ Over $75 \%$ of patients were also receiving metformin at a stable dose. During the course of this study, cardiac disorders occurred more frequently in patients receiving alogliptin (6.5\% for alogliptin $25.0 \mathrm{mg}, 3 \%$ for alogliptin $12.5 \mathrm{mg}$, and $1.0 \%$ for placebo). Six patients experienced severe cardiac AEs within the alogliptin treatment arms, and two patients taking alogliptin $25 \mathrm{mg}$ experienced cardiac AEs that were considered possibly drug related (palpations of moderate intensity in one patient and congestive heart failure of moderate intensity in another). Frequencies of drug-related AEs, serious AEs, and discontinuations due to AEs were similar across all groups. Peripheral edema occurred slightly less frequently in the alogliptin $12.5 \mathrm{mg}$ and $25.0 \mathrm{mg}$ cohorts than in the placebo group $(6.1 \%, 5.5 \%$, and $7.2 \%$, respectively). Headache, upper respiratory tract infections, and gastrointestinal AEs occurred with similar frequency between cohorts. Sinusitis and bronchitis occurred slightly less frequently in the alogliptin treatment groups, while AEs involving both infection/ infestation and skin/subcutaneous tissue occurred at higher rates in patients receiving alogliptin.

Kaku et al examined alogliptin as add-on to pioglitazone in 339 Japanese participants with T2DM for 12 weeks with a 40-week open-label extension period. ${ }^{23}$ The incidence of AEs was similar for all groups, with $37.8 \%$ for pioglitazone plus $12.5 \mathrm{mg}$ alogliptin, $45.1 \%$ for pioglitazone plus $25.0 \mathrm{mg}$ alogliptin, and $47.8 \%$ for pioglitazone plus placebo. Incidence of drug-related AEs was higher in the alogliptin cohorts, with $7.2 \%, 8.8 \%$, and $6.1 \%$ in the $12.5 \mathrm{mg}, 25.0 \mathrm{mg}$, and placebo groups, respectively. Nasopharyngitis was the most common AE reported, with $4.5 \%$ in the $12.5 \mathrm{mg}$ group, $12.4 \%$ in the $25.0 \mathrm{mg}$ group, and $5.2 \%$ in the placebo group reporting this AE. Edema-related events occurred more frequently in the alogliptin $25.0 \mathrm{mg}$ group than with pioglitazone plus placebo, but no cases were reported within the alogliptin $12.5 \mathrm{mg}$ group. Accordingly, the authors indicated that $12.5 \mathrm{mg}$ may be the optimal alogliptin dose when combined with pioglitazone.

\section{Safety considerations of special interest Pancreatitis}

Individual cases of pancreatitis in animal and human trials of GLP-1 receptor agonists and DPP-4 inhibitors led to initial concern that these agents may increase the risk of pancreatitis. Some histological studies in animals and tissues derived from organ donors demonstrated $\beta$-cell hyperplasia and elevated expression of proliferation markers after exposure to GLP-1 receptor agonists. Because cases of pancreatitis are infrequent, it is difficult to accurately estimate the relative risk. However, post hoc analyses have failed to show an increased risk for diagnosis of, or hospitalization for, pancreatitis in the extensive clinical data available for the GLP-1 agonist exenatide and the DPP-4 inhibitors. ${ }^{15,34}$ In the pooled analysis reported in the US prescribing information for alogliptin, pancreatitis was reported in eleven of 5,902 (0.19\%) participants receiving alogliptin $25 \mathrm{mg}$ daily versus five of 5,183 $(0.096 \%)$ of participants receiving placebo or an active comparator in clinical trials. ${ }^{35}$ The EXamination of cArdiovascular outcoMes with alogliptIN versus standard of carE in patients with type 2 diabetes mellitus and acute coronary syndrome (EXAMINE) trial, likewise, reported pancreatitis rates for alogliptin similar to placebo in over 7,800 patient-years of observation. ${ }^{36}$ Although the available data do not show any significantly increased incidence or consistent trends in support of a link to pancreatitis with 
alogliptin or other DPP-4 inhibitors, published prescribing information cautions providers to discontinue alogliptin if pancreatitis is suspected and to initiate therapy with caution in individuals with a history of pancreatitis. ${ }^{35}$

\section{Fluid retention and edema}

Edema and weight gain are both common AEs associated with pioglitazone. ${ }^{23}$ An increased incidence of edema has been reported when other DPP-4 inhibitors are added to pioglitazone. ${ }^{23}$ Kaku et al and Pratley et al reported no increased incidence of edema-related events in studies of 52-weeks and 26-weeks duration, respectively. ${ }^{23,26}$ Kaku and colleagues reported that adding alogliptin to pioglitazone was linked to weight gain and abdominal circumference increases that were small and not clinically significant (weight changes ranging from -0.03 to $0.46 \mathrm{~kg}){ }^{23}$ Another trial reported peripheral edema at a rate of $4 \%$ (16 of 404 participants) in a group receiving alogliptin $25 \mathrm{mg}$ with pioglitazone $30 \mathrm{mg}$ and stable metformin dosing, compared with $4.5 \%$ (18 of 399 participants) in a group receiving only stable metformin with an up-titration of pioglitazone to $45 \mathrm{mg}$ daily. ${ }^{25}$ Across all studies reviewed, no obvious difference in the incidence of edema-related events was evident with the addition of alogliptin to pioglitazone and/or metformin. That said, the thiazolidinediones are known to contribute to edema and should be used cautiously in individuals at risk for fluid retention.

\section{Cardiovascular safety}

Heart disease, stroke, and other cardiovascular (CV) events occur more frequently in people with T2DM. Long-term CV outcomes and CV-risk-factor modification are thus issues of particular interest for current and future antihyperglycemic therapies. The results of a number of preclinical and clinical studies have led to postulation that DPP-4 inhibitors may actually improve markers of $\mathrm{CV}$ disease. ${ }^{37}$ Eliasson et al reported significant reductions in postprandial triglycerides and lipoproteins with alogliptin plus pioglitazone dual therapy. ${ }^{38}$ Long-term alogliptin exposure has also been found to reduce atherosclerosis and inflammation in animal models, via changes in leukocyte chemotaxis and monocyte recruitment. ${ }^{39,40}$ In a study of Japanese patients with T2DM, adding alogliptin $25 \mathrm{mg}$ to pioglitazone resulted in statistically significant reductions in total cholesterol $(-5.7 \mathrm{mg} / \mathrm{dL}$, $\mathrm{SD}=21.1)$ and free fatty acids $(-0.04 \mathrm{mg} / \mathrm{dL}, \mathrm{SD}=0.20)$ relative to pioglitazone alone, with a visible trend toward the reduction of all serum lipid parameters. ${ }^{23}$ While these data are promising, prospective $\mathrm{CV}$ outcomes data are required to substantiate such findings with these and other surrogate markers of $\mathrm{CV}$ disease.

The EXAMINE trial, initiated in 2011 and completed in 2013, was conducted as a comprehensive evaluation of the safety profile of alogliptin in patients at high risk for $\mathrm{CV}$ events. The trial included 5,380 patients with preexisting acute coronary syndrome, randomized to receive either alogliptin or placebo and followed for up to 40 months (median 18 months). ${ }^{36}$ The primary end point was a composite outcome inclusive of CV-related death, nonfatal myocardial infarction, and nonfatal stroke. The primary composite end point occurred in $11.3 \%$ of alogliptin recipients and in $11.8 \%$ of those receiving placebo (hazard ratio $0.96 ; P<0.001$ for noninferiority). Secondary end points included all-cause mortality and total CV mortality. No significant differences were seen between groups for the rate of CV mortality (3.3\% vs $4.1 \%)$, nonfatal myocardial infarction $(6.9 \%$ vs $6.5 \%)$, or nonfatal stroke (1.1\% vs $1.2 \%)$. Analysis on completion showed no significant differences in any end point or in any individual composite end point, although the alogliptin cohort showed nonsignificant sub-unitary hazard ratios (favoring the addition of alogliptin) in four out of five of the CV event types included in the analysis. Rates of hypoglycemia, cancer, pancreatitis, and initiation of dialysis were also similar between groups. Although the EXAMINE trial demonstrated non-inferiority to placebo in CV safety, the investigators noted that the median treatment duration of 18 months meant that risks or benefits associated with longer-term use could not be ruled out.

\section{Availability and administration}

Alogliptin (Nesina ${ }^{\circledR}$; Takeda Pharmaceutical Company) is available as $6.25,12.5$, and $25.0 \mathrm{mg}$ tablets. The recommended starting dose is $25 \mathrm{mg}$ once daily in people with T2DM. It is recommended that the dose be decreased in patients with renal impairment, with a dose reduction to $12.5 \mathrm{mg}$ once daily in individuals with a creatinine clearance $(\mathrm{CrCl})$ of $30-59 \mathrm{~mL} /$ minute, and a further reduction to $6.25 \mathrm{mg}$ once daily with a $\mathrm{CrCl}$ of $<30 \mathrm{~mL} /$ minute. ${ }^{35}$

Alogliptin in fixed-dose combination with metformin (Kazano) is available in 12.5/1,000.0 mg and 12.5/500.0 mg tablets. ${ }^{41}$ Twice-daily dosing is recommended to achieve a total daily dose of $25 \mathrm{mg}$ of alogliptin. Because alogliptin and metformin are both eliminated via the kidneys, dosing adjustments are recommended based on $\mathrm{CrCl}$. This product is not recommended to be initiated in patients with a $\mathrm{CrCl}<45 \mathrm{~mL} /$ minute and is contraindicated with a $\mathrm{CrCl}<30 \mathrm{~mL} / \mathrm{minute}$, in accordance with current recommendations for metformin use. ${ }^{42}$ 
Alogliptin in fixed-dose combination with pioglitazone (Oseni) is commercially available in several combinations: $12.5 / 15.0 \mathrm{mg}, 12.5 / 30.0 \mathrm{mg}, 12.5 / 45.0 \mathrm{mg}, 25.0 / 15.0 \mathrm{mg}$, 25.0/30.0 mg, and 25.0/45.0 mg tablets. ${ }^{43}$ The recommended starting dose is $25.0 / 15.0 \mathrm{mg}$ or $25.0 / 30.0 \mathrm{mg}$ once daily followed by individualized dose titration based on $\mathrm{A} 1 \mathrm{c}$ response and individualized treatment goals. Caution is recommended in patients with heart failure, and recipients should be monitored closely for fluid retention. As with other alogliptin products, Oseni should be titrated according to $\mathrm{CrCl}$ to avoid accumulation of the alogliptin component. Of note, alogliptin is the only currently available DPP-4 inhibitor available in fixed-dose combination with pioglitazone.

\section{Discussion}

By inhibiting DPP-4, the enzyme responsible for degrading GIP and GLP-1, DPP-4 inhibitors cause a reduction in ambient blood glucose. Clinical trial data with alogliptin demonstrate clinical efficacy in terms of A1c and FPG reductions when used both as monotherapy and in combination with other oral antidiabetic medications. ${ }^{20-28}$ Overall, alogliptin is generally well tolerated when used as monotherapy and in combination with concomitant oral antidiabetic therapies. The most recent clinical practice recommendations from the American Diabetes Association recommend DPP-4 inhibitors as an option for second-line addition to metformin and as a component of three-drug combinations with a variety of antihyperglycemic agents. ${ }^{1}$ Likewise, the 2013 American Association of Clinical Endocrinologists' consensus statement noted DPP-4 inhibitors as having possible benefits when used as monotherapy or as a component of dual or triple therapy. ${ }^{2}$ DPP-4 inhibitors are noted as having a low risk of hypoglycemia, a weight-neutral profile, and favorable tolerability when compared with other pharmacological agents for the treatment of T2DM. DPP-4 inhibitors, such as alogliptin, additionally play a potentially important role in combination therapy due to the benefit of utilizing agents with complementary mechanisms of action.

Alogliptin in combination with metformin provides two distinct mechanisms with the potential for some clinically advantageous overlaps. The glucose-lowering effects of metformin are primarily attributed to modulation of metabolic signaling in the liver and muscle tissues, leading to reduced gluconeogenesis and hepatic glucose output and increased glucose uptake in muscle. ${ }^{44,45}$ Metformin has also been shown to significantly increase postprandial GLP-1 levels through mechanisms unrelated to DPP-4 inhibition, ${ }^{45}$ although clinically significant complementary effects were not directly observed in alogliptin/metformin combination studies. ${ }^{46}$
Hence, the pharmacology of alogliptin and metformin may be regarded as independent and complementary. The use of alogliptin in combination with pioglitazone is likewise rational if seeking agents with complementary mechanisms of action. Pioglitazone stimulates the peroxisome proliferator-activated receptor gamma, signaling changes in gene transcription that ultimately result in enhanced insulin response in hepatic, adipose, and skeletal muscle tissues. ${ }^{47}$ Of note, alogliptin is the only DPP-4 inhibitor currently available commercially in fixed-dose combination with a thiazolidinedione.

In terms of safety, DPP-4 inhibitors are generally well tolerated and demonstrate similar SE profiles in clinical trials. As highlighted in Table 2, alogliptin in combination with metformin and pioglitazone was generally well tolerated in the clinical trial setting. One critical advantage of such combinations is the low risk of hypoglycemia - perhaps of significant clinical importance in the elderly. A pooled analysis of data pertaining to alogliptin use in patients ages 65 to 80 was conducted by Pratley et al in 2009. ${ }^{48}$ Alogliptin was generally found to be safe and well tolerated in elderly patients, and no meaningful differences were apparent in the overall rates of AEs compared with patients aged 18-64. A higher percentage of elderly patients experienced a serious AE; however, this trend was evident in both the placebo and alogliptin groups and may be due only to the differences in age. No difference in weight gain was observed across treatment groups or between age groups. In elderly patients, the highest incidences of hypoglycemia of all severity levels were reported for the placebo group. The study authors noted that severe hypoglycemia is associated with increased mortality in elderly patients, so an opportunity to enhance glycemic control without increasing this treatment-limiting risk is an appealing possibility. ${ }^{48}$ Of additional importance in elderly individuals, dose titration based on renal function is necessary with alogliptin. Assessment of renal function and appropriate dose titration is additionally warranted with metformin for those individuals receiving alogliptin plus metformin combination therapy.

However, additional safety concerns have recently arisen regarding a potential link between DPP-4 inhibitor use and the occurrence of pancreatitis. While there is some debate regarding whether the reported cases of pancreatitis are in fact attributable to DPP-4 inhibitor use, the US Food and Drug Administration recommends that patients be monitored carefully for the development of pancreatitis during the initiation and upward titration of these agents.

\section{Conclusion}

Clinical efficacy data support the use of alogliptin in combination with metformin and pioglitazone in the treatment 
of T2DM. Due to the progressive nature of T2DM, multiple agents addressing different, yet complementary, mechanisms of action are frequently needed to achieve individualized glycemic goals. Given the multitude of medications often taken by individuals with T2DM, fixed-dose products provide an option for practitioners to decrease the pill burden placed on patients. Alogliptin in fixed-dose combination with metformin (Kazano) and pioglitazone (Oseni) offer a welcome option for patients and providers wishing to simplify complex medication regimens.

\section{Disclosure}

DQH reports no conflicts of interest in this work. JJN receives institutional research grant support from Amylin, AstraZeneca, Johnson \& Johnson, Merck, and Novo Nordisk. JJN serves as a consultant to Janssen Pharmaceuticals and Sanofi. No financial support was received for writing this article. The authors declare no other conflicts of interest in this work.

\section{References}

1. American Diabetes Association. Standards of medical care in diabetes 2014. Diabetes Care. 2014; 37 Suppl 1:S14-S80.

2. Garber AJ, Abrahamson MJ, Barzilay JI, et al. American Association of Clinical Endocrinologists' comprehensive diabetes management algorithm 2013 consensus statement. Endocr Pract. 2013;19(Suppl 2): $1-48$.

3. Pratley RE, Kipnes MS, Fleck PR, Wilson C, Mekki Q; Alogliptin Study 007 Group. Efficacy and safety of the dipeptidyl peptidase-4 inhibitor alogliptin in patients with type 2 diabetes inadequately controlled by glyburide monotherapy. Diabetes Obes Metab. 2009;11(2): 167-176.

4. Rosenstock J, Rendell MS, Gross JL, Fleck PR, Wilson CA, Mekki Q. Alogliptin added to insulin therapy in patients with type 2 diabetes reduces $\mathrm{HbA}(1 \mathrm{C})$ without causing weight gain or increased hypoglycaemia. Diabetes Obes Metab. 2009;11(12):1145-1152.

5. Nauck MA, Homberger E, Siegel EG, et al. Incretin effects of increasing glucose loads in man calculated from venous insulin and C-peptide responses. J Clin Endocrinol Metab. 1986;63(2): 492-498.

6. Drucker DJ, Nauck MA. The incretin system: glucagon-like peptide-1 receptor agonists and dipeptidyl peptidase- 4 inhibitors in type 2 diabetes. Lancet. 2006;368(9548):1696-1705.

7. Mentis N, Vardarli I, Köthe LD, et al. GIP does not potentiate the antidiabetic effects of GLP-1 in hyperglycemic patients with type 2 diabetes. Diabetes. 2011;60(4):1270-1276.

8. Covington P, Christopher R, Davenport M, et al. Pharmacokinetic, pharmacodynamic, and tolerability profiles of the dipeptidyl peptidase-4 inhibitor alogliptin: a randomized, double-blind, placebo-controlled, multiple-dose study in adult patients with type 2 diabetes. Clin Ther. 2008;30(3):499-512.

9. Nauck MA, Niedereichholz U, Ettler R, et al. Glucagon-like peptide 1 inhibition of gastric emptying outweighs its insulinotropic effects in healthy humans. Am J Physiol. 1997;273(5 Pt 1):E981-E988.

10. Nauck MA, Heimesaat MM, Orskov C, Holst JJ, Ebert R, Creutzfeldt W. Preserved incretin activity of glucagon-like peptide 1 [7-36 amide] but not of synthetic human gastric inhibitory polypeptide in patients with type-2 diabetes mellitus. J Clin Invest. 1993;91(1):301-307.

11. Baetta R, Corsini A. Pharmacology of dipeptidyl peptidase-4 inhibitors: similarities and differences. Drugs. 2011;71(11):1441-1467.
12. Golightly LK, Drayna CC, McDermott MT. Comparative clinical pharmacokinetics of dipeptidyl peptidase-4 inhibitors. Clin Pharmacokinet. 2012;51(8):501-514.

13. Christopher R, Covington P, Davenport M, et al. Pharmacokinetics, pharmacodynamics, and tolerability of single increasing doses of the dipeptidyl peptidase- 4 inhibitor alogliptin in healthy male subjects. Clin Ther. 2008;30(3):513-527.

14. Scott LJ. Alogliptin: a review of its use in the management of type 2 diabetes mellitus. Drugs. 2010;70(15):2051-2072.

15. Nauck MA. A critical analysis of the clinical use of incretin-based therapies: The benefits by far outweigh the potential risks. Diabetes Care. 2013;36(7):2126-2132.

16. Scheen AJ. Dipeptidylpeptidase-4 inhibitors (gliptins): focus on drugdrug interactions. Clin Pharmacokinet. 2010;49(9):573-588.

17. Karim A, Fleck P, Dorsey D, Zhang W, Mekki Q, Preston RA. Single dose pharmacokinetics of alogliptin benzoate(SYR-322) in subjects with moderate hepatic impairment: Thirty - Sixth Annual Meeting American College of Clinical Pharmacology, San Francisco, CA, USA, 9-11 September 2007. J Clin Pharmacol. 2007;47(9):1207.

18. Karim A, Fleck P, Harrell RE, et al. Effects of age, race, and gender on the pharmacokinetics and pharmacodynamics of alogliptin, a novel and highly selective dipeptidyl peptidase-4 inhibitor, in healthy subjects. Clin Pharmacol Ther. 2008;83(Suppl 1):PI-14.

19. Karim A, Covington P, Christopher R, et al. Pharmacokinetics of alogliptin when administered with food, metformin, or cimetidine: a two-phase, crossover study in healthy subjects. Int J Clin Pharmacol Ther. 2010;48(1):46-58.

20. Nauck MA, Ellis GC, Fleck PR, Wilson CA, Mekki Q; Alogliptin Study 008 Group. Efficacy and safety of adding the dipeptidyl peptidase-4 inhibitor alogliptin to metformin therapy in patients with type 2 diabetes inadequately controlled with metformin monotherapy: a multicentre, randomised, double-blind, placebo-controlled study. Int J Clin Pract. 2009;63(1):46-55.

21. Seino Y, Miyata Y, Hiroi S, Hirayama M, Kaku K. Efficacy and safety of alogliptin added to metformin in Japanese patients with type 2 diabetes: a randomized, double-blind, placebo-controlled trial with an open-label, long-term extension study. Diabetes Obes Metab. 2012;14(10):927-936.

22. Rosenstock J, Inzucchi SE, Seufert J, Fleck PR, Wilson CA, Mekki Q. Initial combination therapy with alogliptin and pioglitazone in drug-naïve patients with type 2 diabetes. Diabetes Care. 2010;33(11):2406-2408.

23. Kaku K, Itayasu T, Hiroi S, Hirayama M, Seino Y. Efficacy and safety of alogliptin added to pioglitazone in Japanese patients with type 2 diabetes: a randomized, double-blind, placebo-controlled trial with an open-label longterm extension study. Diabetes Obes Metab. 2011;13(11):1028-1035.

24. DeFronzo RA, Burant CF, Fleck P, Wilson C, Mekki Q, Pratley RE. Efficacy and tolerability of the DPP-4 inhibitor alogliptin combined with pioglitazone, in metformin-treated patients with type 2 diabetes. J Clin Endocrinol Metab. 2012;97(5):1615-1622.

25. Bosi E, Ellis GC, Wilson CA, Fleck PR. Alogliptin as a third oral antidiabetic drug in patients with type 2 diabetes and inadequate glycaemic control on metformin and pioglitazone: a 52-week, randomized, doubleblind, active-controlled, parallel-group study. Diabetes Obes Metab. 2011;13(12):1088-1096.

26. Pratley RE, Reusch JE, Fleck PR, Wilson CA, Mekki Q; Alogliptin Study 009 Group. Efficacy and safety of the dipeptidyl peptidase-4 inhibitor alogliptin added to pioglitazone in patients with type 2 diabetes: a randomized, double-blind, placebo-controlled study. Curr Med Res Opin. 2009;25(10):2361-2371.

27. DeFronzo RA, Fleck PR, Wilson CA, Mekki Q; Alogliptin Study 010 Group. Efficacy and safety of the dipeptidyl peptidase-4 inhibitor alogliptin in patients with type 2 diabetes and inadequate glycemic control: a randomized, double-blind, placebo-controlled study. Diabetes Care. 2008;31(12):2315-2317.

28. Kutoh E, Ukai Y. Alogliptin as an initial therapy in patients with newly diagnosed, drug naïve type 2 diabetes: a randomized, control trial. Endocrine. 2012;41(3):435-441. 
29. Sakai Y, Suzuki A, Mugishima K, et al. Effects of alogliptin in chronic kidney disease patients with type 2 diabetes. Intern Med. 2014;53(3): 195-203.

30. Hattori S. Sitagliptin reduces albuminuria in patients with type 2 diabetes. Endocr J. 2011;58(1):69-73.

31. Hocher B, Reichetzeder C, Alter ML. Renal and cardiac effects of DPP4 inhibitors - from preclinical development to clinical research. Kidney Blood Press Res. 2012;36(1):65-84.

32. Nakamura Y, Inagaki M, Shimizu T, et al. Long-term effects of alogliptin benzoate in hemodialysis patients with diabetes: a 2-year study. Nephron Clin Pract. 2013;123(1-2):46-51.

33. Fujii Y, Abe M, Higuchi T, et al. The dipeptidyl peptidase-4 inhibitor alogliptin improves glycemic control in type 2 diabetic patients undergoing hemodialysis. Expert Opin Pharmacother. 2013;14(3):259-267.

34. Li L, Shen J, Bala MM, et al. Incretin treatment and risk of pancreatitis in patients with type 2 diabetes mellitus: systematic review and meta-analysis of randomised and non-randomised studies. BMJ. 2014;348:g2366.

35. Nesina ${ }^{\mathrm{TM}}$ (alogliptin) [package insert]. Deerfield, IL: Takeda Pharmaceuticals America, Inc.; 2013.

36. White WB, Bakris GL, Bergenstal RM, et al. EXamination of cArdiovascular outcoMes with alogliptIN versus standard of carE in patients with type 2 diabetes mellitus and acute coronary syndrome (EXAMINE): a cardiovascular safety study of the dipeptidyl peptidase 4 inhibitor alogliptin in patients with type 2 diabetes with acute coronary syndrome. Am Heart J. 2011;162(4):620-626. e1.

37. Kapoor S. Potent antiatherosclerotic effects of alogliptin in addition to its potent antidiabetic effects. Diabetes Metab Syndr Obes. 2012;5: 121-123.
38. Eliasson B, Möller-Goede D, Eeg-Olofsson K, et al. Lowering of postprandial lipids in individuals with type 2 diabetes treated with alogliptin and/or pioglitazone: a randomised double-blind placebocontrolled study. Diabetologia. 2012;55(4):915-925.

39. Shah Z, Kampfrath T, Deiuliis JA, et al. Long-term dipeptidylpeptidase 4 inhibition reduces atherosclerosis and inflammation via effects on monocyte recruitment and chemotaxis. Circulation. 2011;124(21):2338-2349

40. Shah Z, Pineda C, Kampfrath T, et al. Acute DPP-4 inhibition modulates vascular tone through GLP-1 independent pathways. Vascul Pharmacol. 2011;55(1-3):2-9.

41. Kazano ${ }^{\mathrm{TM}}$ (alogliptin and metformin $\mathrm{HCl}$ ) [package insert]. Deerfield, IL: Takeda Pharmaceuticals America, Inc.; 2013.

42. Lipska KJ, Bailey CJ, Inzucchi SE. Use of metformin in the setting of mild-to-moderate renal insufficiency. Diabetes Care. 2011;34(6): 1431-1437.

43. Oseni ${ }^{\mathrm{TM}}$ (alogliptin and pioglitazone) [package insert]. Deerfield IL: Takeda Pharmaceuticals America, Inc.; 2013.

44. Scheen AJ. GLP-1 receptor agonists or DPP-4 inhibitors: how to guide the clinician? Ann Endocrinol (Paris). 2013;74(5-6):515-522.

45. Andújar-Plata P, Pi-Sunyer X, Laferrère B. Metformin effects revisited. Diabetes Res Clin Pract. 2012;95(1):1-9.

46. Andukuri R, Drincic A, Rendell M. Alogliptin: a new addition to the class of DPP-4 inhibitors. Diabetes Metab Syndr Obes. 2009;2:117-126.

47. Hanefeld M. Pioglitazone and sulfonylureas: effectively treating type 2 diabetes. Int J Clin Pract Suppl. 2007;(153):20-27.

48. Pratley RE, McCall T, Fleck PR, Wilson CA, Mekki Q. Alogliptin use in elderly people: a pooled analysis from phase 2 and 3 studies. $J \mathrm{Am}$ Geriatr Soc. 2009;57(11):2011-2019.

\section{Publish your work in this journal}

Diabetes, Metabolic Syndrome and Obesity: Targets and Therapy is an international, peer-reviewed open-access journal committed to the rapid publication of the latest laboratory and clinical findings in the fields of diabetes, metabolic syndrome and obesity research. Original research, review, case reports, hypothesis formation, expert opinion and commentaries are all considered for publication. The manuscript management system is completely online and includes a very quick and fair peer-review system, which is all easy to use. Visit http://www.dovepress.com/testimonials.php to read real quotes from published authors. 